\title{
Spiral of Silence on Social Media: Study on Political Posting in Indonesia
}

\author{
Narendra Ghaniy Putra ${ }^{1}$, and Eriyanto Eriyanto ${ }^{2}$ \\ ${ }^{1,2}$ Faculty of Social and Political Sciences, Univesitas Indonesia, Indonesia
}

eriyanto09@ui.ac.id ${ }^{2}$

\begin{abstract}
This is a study about spiral of silence effect in social media, with the concentration to willingness to self censorship and political posting activity behaviour. The condition that showed social media has become a convenient medium to show political opinion of its users had pumped the curiosity of the authors to know about the modified model that impact to spiral of silence effect on social media. This study used quantitative research through the dissemination of cross sectional design online questionnaire to the daily board of the Student Council in Universitas Indonesia. The collected data then processed by statistical calculations. The result of this study is the spiral of silence effect had a modified model that make it shown among Indonesian social media users, such as Facebook, Twitter, Instagram, Line, and Whatsapp.
\end{abstract}

Keywords: Spiral of Silence, Willingness to Self Censorship, Political Posting Activity, Social Media.

\section{Introduction}

Internet access has indeed had a positive effect on several indicators of community involvement in a political context [1] Jennings and Zeitner states that the internet is an extraordinary tool for motivating and inviting people to be politically involved with the amount of public information that was once hard to come by or out of reach now accessible through the internet. Referring to these descriptions, it is not surprising that the internet has now become a tool that is able to actively encourage community involvement and political participation in various forms of participation, such as through political posts on social media.

Political posting is a form of individual reaction to addressing political issues circulating online on social media [2]. On social media Facebook, Twitter, Instagram, Line and Whatsapp political posts can be in the form of status (text upload), sharing news narrative links (uploading news texts that are generally connected to online news pages that are integrated directly with the main site), image sharing (upload pictures of their own or other social media users), share videos (upload their own videos or other social media users who are generally connected to video sharing sites Youtube.com or other video sharing sites), comments (uploaded text entered in the status, images, or videos shared by other social media users), or a combination of all of them considering the capabilities of social media Facebook, Twitter, Instagram, Line, and Whatsapp which are currently able to accommodate all forms of upload that the user wants.

The increasing political participation of people through political posts on social media makes us need to question the existence of the effects of spiral of silence on social media. Simply put, 
mass media effect theory says that humans are afraid of experiencing social isolation, thus motivating them to observe and determine social standards in the social environment through adjusting their behavior in public in accordance with observed standards [3][2]. If in conventional media public information exposure is a key component that causes fear to be isolated so individuals need to make social adjustments[3] .So it needs to be realized that the boundaries that make the spiral of silence effect appear blurred on social media are the habits of fear of isolation, given that there has been an increase in political participation in the form of uploading political posts[2].

Based on the above problems, the purpose of this research is to examine whether the spiral of silence effect is still valid among social media users in Indonesia?

\section{Theoretical Review}

The study of the spiral of silence theory has become one of the studies that is popular in the communication science family[4][5][2].Starting from the research of Noelle Elizabeth Neumann who examined the process of the formation of public opinion which turned out to show a spiral phenomenon of one's efforts in addressing public opinion to avoid social isolation and is one part of the study of mass media effects[4], to develop into the realm of digital media studies that are commonly used by people today.

In its development, found several factors forming the spiral effect in the online world that are different from the classical studies. Like research conducted by [5] where the feeling of atakut will experience social isolation is divided into two parts, namely the fear of experiencing isolation in the real world and in cyberspace, or involving a variable willingness to self-censor as done by Kwon[2]

So, how can the spiral of silence effect form on social media Facebook, Twitter, Instagram, Line, and Whatsapp? Referring to several previous studies that have been summarized, we found that there are several concepts that play an important role in shaping the spiral effect on social media. The research model that we proposed is as follows:

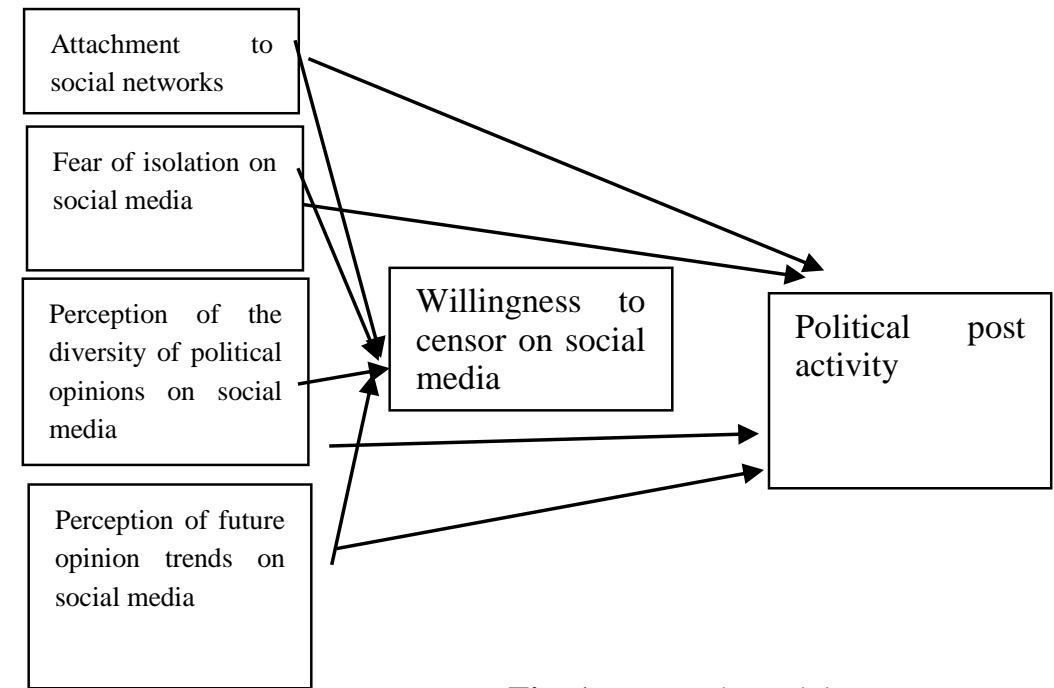

Fig. 1. Research model 
H1: The attachment to someone's intimate social network that is connected to social media influences a person's willingness to self-censor on social media[2].

$\mathrm{H} 2$ : The attachment of an intimate social network to someone who is connected on social media influences the activity of posting one's politics on social media [2].

$\mathrm{H} 3$ : Fear of experiencing isolation on social media affects one's willingness to self-censor social media[5].

H4: Fear of experiencing isolation on social media influences the activity of posting one's politics on social media[2].

H5: Perceptions of the diversity of political opinions on social media affect one's willingness to self-censor on social media[2].

H6: Perception of the diversity of political opinions on social media influences the activity of posting one's politics on social media[2].

H7: Perceptions of future political opinion trends on social media affect one's willingness to self-censor on social media[4].

H8: Perceptions of future political opinion trends on social media affect the activity of posting one's politics on social media[4].

H9: A person's willingness to self-censor on social media influences the activity of posting one's politics on social media[2].

\section{Research Methods}

This research is a research with quantitative approach and positivism paradigm. In conducting data collection, we conducted an online survey method with a questionnaire that contained the concepts of supporting spiral of silence that were associated with the "Zaadit Yellow Card" event. This event took the form of a "yellow card" action to President Joko Widodo conducted by Zaadit Taqwa when the President attended the University of Indonesia's 68th Anniversary (2/2/2018). The survey we proposed was cross sectional in design, or designed for research only once.

The population we are aiming for are students who are members of the Executive Board body of the faculty-level BEM organization in the UI campus, totaling 983 people. After determining the margin of error or tolerated allowance of inaccuracy of $6.4 \%$, the number of ideal samples that we submitted is 190 people. Sampling in this study was conducted using nonprobability sampling method with snowball technique. Where, the sample criteria that we set in this study were S1 and D3 students who joined the Executive Board of the BEM at the faculty level at the University of Indonesia and were active in the use of social media Facebook, Twitter, Instagram, Line, and Whatsapp with age demographics ranging from 18 for up to 22 years.

As shown through the research model that we proposed (Figure 1), it can be explained that we put: The Intimate Social Network Attachment in Social Media[2] ;Fear Is Isolated in Social Media [5] Perception of the Diversity of Political Opinions in Social Media[2];and Perceptions of Future Political Opinion Trends in Social Media[4] as independent variables in this study. Meanwhile, for the concept of Willingness to Conduct Self Censorship in Social Media[2] we put it into two positions, namely as the dependent variable in Sub Structure I regression testing, and as an independent variable in Sub Structure II regression testing. The last concept that we proposed in this study was Political Posting Activities [2] positioned as the dependent variable. Later, we will measure the direct effects, indirect effects, and total effects generated by each concept on Political Posting Activities[2] using path analysis, where the analysis model is the development of a regression analysis model. 


\section{Results}

The first test we did after the research data we successfully collected was the multivariate regression test in the Sub-Structure I of the study, namely: The Influence of Intimate Social Networking (X1); Fear of experiencing isolation on social media (X2); Perception of the Diversity of Political Opinions on Social Media (X3); and Perception in Future Trend of Political Opinion in Social Media (X4); on Willingness to Conduct Self Sensors in Social Media (Y1).

Table 1. Summary of Hypothesis Test Results Sub Structure I

\begin{tabular}{|l|r|r|r|r|}
\hline Model & $\mathrm{R}$ & $\begin{array}{c}\mathrm{R} \\
\text { Square }\end{array}$ & $\begin{array}{c}\text { Adjusted R } \\
\text { Square }\end{array}$ & $\begin{array}{c}\text { Std. Error of } \\
\text { the Estimate }\end{array}$ \\
\hline 1 & $.410^{\mathrm{a}}$ & .168 & .150 & .79743 \\
\hline
\end{tabular}

Referring to the table above, it is shown that the R Square value of the five variables is 0.168 , which means that $16.8 \%$ of a person's willingness to self-censor on social media is influenced by the attachment of intimate social networks; fear of experiencing isolation on social media; perception of the diversity of political opinions on social media; and perceptions of trends in the development of future political opinions on social media, while $83.2 \%$ of willingness to selfcensor on social media is influenced by other factors outside of this study. Then, through the results shown in the table too, we can determine the error value 1 by using the formula: $1=\sqrt{ }$ (1- Rsquare), so the value of e $1=\sqrt{ }(1-0,168)=0.9121$.

To see how much the correlation coefficient between the independent variables and the dependent variable in this substructure can be seen in the $\mathrm{R}$ value contained in the table above, which is 0.410 . Where, these values can be categorized into correlations being towards strong.

Table 2. Coefficient of Sub Structure I

\begin{tabular}{|c|c|c|c|c|c|}
\hline \multirow{2}{*}{ Variable } & \multicolumn{2}{|c|}{$\begin{array}{c}\text { Unstandardized } \\
\text { Coefficients }\end{array}$} & \multirow{2}{*}{$\begin{array}{c}\text { Standardi } \\
\text { zed } \\
\text { Coefficie } \\
\text { nts Beta }\end{array}$} & \multirow{2}{*}{$\mathrm{t}$} & \multirow{2}{*}{ Sig. } \\
\hline & B & $\begin{array}{l}\text { Std. } \\
\text { Error }\end{array}$ & & & \\
\hline (Constant) & .898 & .407 & & 2.205 & .029 \\
\hline $\begin{array}{l}\text { Attachment to } \\
\text { social networks }\end{array}$ & .276 & .150 & .135 & 1.841 & .067 \\
\hline $\begin{array}{c}\text { Fear of isolation } \\
\text { on social media }\end{array}$ & .507 & .103 & .354 & 4.917 & .000 \\
\hline $\begin{array}{l}\text { Perception of the } \\
\text { diversity of } \\
\text { political opinions } \\
\text { on social media }\end{array}$ & .101 & .116 & .064 & .872 & .384 \\
\hline $\begin{array}{l}\text { Perception of } \\
\text { future opinion } \\
\text { trends on social } \\
\text { media }\end{array}$ & -.147 & .100 & -.104 & $1 . \overline{470}$ & .143 \\
\hline
\end{tabular}

Dependent Variable: Willingness to censor on social media 
The next step, we can see the table above which shows the test results of the independent variables on the dependent variable in Sub Structure I. The level of significance we use is 5\%, while the critical area to reject Ho is when the significance value (Pvalue) is less than 0,05 . Referring to the table, the significance value generated by variable X1 (Intimate Social Network Attachment) to Y1 (Willingness to Conduct Self Sensors in Social Media) is 0.067. Thus, it can be stated that there is no significant direct effect of intimate social network attachment on the willingness to self-censor on social media.

Then the significance value generated by variable X2 (Fear of Experiencing Social Isolation) to Y1 (Willingness to Conduct Self-Sensors in Social Media) is 0,000. So it can be concluded, there is a significant direct effect of fear of experiencing social isolation on the willingness to self-censor on social media.

Furthermore, the significance value generated by the variable X3 (Perception on Political Opinion Diversity in Social Media) to Y1 (Willingness to Conduct Self Sensors in Social Media) is 0.384 . Through these results, it can be stated that there is no significant direct effect of the perception on political opinion in social media on the willingness to self-censor on social media.

Finally, the significance value produced by the X4 variable (Perception in Future Trend of Political Opinion Development on Social Media) to Y1 (Willingness to Conduct Self-Sensors in Social Media) is 0.143 . This value illustrates that there is no significant direct effect of perceptions on trends in the development of political opinions on social media on the willingness to self-censor on social media.

The next test we did was a multivariate regression test in Sub Structure II research by testing the variables: Intimate Social Network Attachment (X1); Fear of experiencing isolation on social media (X2); Perception of the Diversity of Political Opinions on Social Media (X3); Perception in the Future Trend of Political Opinion in Social Media (X4); and Willingness to Conduct Self Sensors in Social Media (Y1) on Political Posting Activities on Social Media (Y2).

Table 3. Summary of Hypothesis Test Results Sub Structure II

\begin{tabular}{|c|c|c|c|c|}
\hline Model & $\mathrm{R}$ & R Square & $\begin{array}{c}\text { Adjusted R } \\
\text { Square }\end{array}$ & $\begin{array}{c}\text { Std. Error of } \\
\text { the Estimate }\end{array}$ \\
\hline 1 & $.501^{\mathrm{a}}$ & .251 & .230 & .72523 \\
\hline
\end{tabular}

a. Predictors: (Constant), Y1, X4, X3, X1, X2

The table above shows that the R Square value of the six variables is 0.251 , which means that $25.1 \%$ of a person's willingness to engage in political posting activities on social media is influenced by the attachment of intimate social networks; fear of experiencing isolation on social media; perception of the diversity of political opinions on social media; perception of trends in the development of future political opinions on social media; and willingness to self-censor on social media, while $74.9 \%$ of political posting activities on social media are influenced by other factors outside this research. Through the results shown in the table, we can determine the value of 2 by using the formula:

$\mathrm{e} 2=\sqrt{ }(1-$ Rsquare $)$, so the value of e $2=\sqrt{ }(1-0,251)=0.8654$.

To see how much the correlation coefficient between independent variables and the dependent variable in this substructure can be seen in the $\mathrm{R}$ value, which is 0.501 . This value can be categorized into strong towards very strong. 
Multivariate regression test is then carried out on the independent variable on the dependent variable in Sub Structure II, where the results of the test are as described in the table below. The level of significance we use in this test is $5 \%$, while the critical area to reject Ho is when the significance value ( $\mathrm{P}$ value) is less than 0.05. Referring to the table, the significance value generated by variable X1 (Intimate Social Network Attachment) on Y2 (Political Post Activity on Social Media) is 0.024 . These results illustrate that there is a significant direct effect of intimate social network attachments on political posting activities on social media.

Table 4. Coefficient of Sub Structure II

\begin{tabular}{|c|c|c|c|c|c|}
\hline \multirow{2}{*}{ Variable } & \multicolumn{2}{|c|}{$\begin{array}{l}\text { Unstandardized } \\
\text { Coefficients }\end{array}$} & \multirow{2}{*}{$\begin{array}{c}\text { Standardized } \\
\text { Coefficients } \\
\text { Beta }\end{array}$} & \multirow{2}{*}{$\mathrm{t}$} & \multirow{2}{*}{ Sig. } \\
\hline & B & $\begin{array}{l}\text { Std. } \\
\text { Error }\end{array}$ & & & \\
\hline (Constant) & .975 & .375 & & 2.598 & .010 \\
\hline $\begin{array}{l}\text { Attachment to social } \\
\text { networks }\end{array}$ & .313 & .137 & .161 & 2.278 & .024 \\
\hline $\begin{array}{c}\text { Fear of isolation on social } \\
\text { media }\end{array}$ & -.216 & .100 & -.157 & -2.161 & .032 \\
\hline \begin{tabular}{|c|} 
Perception of the \\
diversity of political \\
opinions on social media
\end{tabular} & .191 & .106 & .126 & 1.798 & .074 \\
\hline $\begin{array}{c}\text { Perception of future } \\
\text { opinion trends on social } \\
\text { media }\end{array}$ & .511 & .091 & .379 & 5.585 & .000 \\
\hline $\begin{array}{l}\text { Willingness to censor on } \\
\text { social media }\end{array}$ & -.209 & .067 & -.218 & -3.120 & .002 \\
\hline
\end{tabular}

Dependent Variable: Political post activity

Then, the significance value generated by variable X2 (Fear of Experiencing Social Isolation) to Y2 (Political Post Activity on Social Media) is 0.032. So it can be concluded, there is a significant direct effect of fear of experiencing social isolation on political posting activities on social media.

Furthermore, the significance value generated by the variable X3 (Perception on the Diversity of Political Opinions on Social Media) to Y2 (Political Post Activity on Social Media) is 0.074 . This value explains that there is no significant direct effect of perceptions on political opinion in social media on political posting activities on social media.

For the significance value generated by variable X4 (Perception in Future Trend of Political Opinion Development on Social Media) to Y2 (Political Posting Activity on Social Media) is 0,000 . This value illustrates that there is a significant direct effect of perceptions on trends in the development of political opinions on social media on the activity of political posting on social media.

Finally, the significance value generated by the variable Y1 (Willingness to Conduct Self Sensors in Social Media) to Y2 (Political Posting Activity on Social Media) is 0.002. Thus, it can be concluded that there is a significant direct effect of willingness to self-censor on social media on political posting activities on social media.

Testing of the fit coefficient model is done to find out which model among the basic models or models that have been adjusted better based on regression testing. The formula used to measure fit coefficients is: 
$\mathrm{x} 2=-(\mathrm{N}-\mathrm{df}) \log \mathrm{Q}$

Where,

$\mathrm{x} 2$ : fit coefficient for the adjusted model

$\mathrm{N}$ : number of samples

df: the number of traces that are modified in the adjusted model

Q: the size of the variation model that cannot be explained between the basic model and adjusted

Referring to the formulation, the model value of the fit coefficient in this study is:

$\mathrm{x} 2=-(\mathrm{N}-\mathrm{df}) \log \mathrm{Q}$

$=-(190-4) \log 1,12100333$

$=-(186) 0.04960690269$

$=-9,22688390034$

Based on these calculations, for a significance level of 0.05 and a degree of freedom $\mathrm{df}=4$, a critical value of 0.705 is obtained. Comparison between critical values and $\times 2$ values indicates that the $\mathrm{x} 2$ value is greater than the critical value. Thus, it can be stated that the adjusted model has a better fit model than the base model. Therefore, the adjusted model is accepted.

\section{Discussion}

As we mentioned earlier, this research is intended to answer the research question "Does the spiral of silence effect still apply among Indonesian social media users?". The question is then broken down into 9 hypotheses that measure the relationship between these variables, where the hypotheses are divided into 2 sub-structures tested using multiple linear regression. The test is then conducted on the students who are members of the organization's daily management of the faculty level Student Executive Board at the University of Indonesia by using the case of "Zaadit Yellow Card" as the object, where the description of the hypotheses can be seen in the following table:

Table 5. Hypotesis Test

\begin{tabular}{|l|l|l|}
\hline & \multicolumn{3}{|c|}{ HYPOTESIS } & CONCLUSION \\
\hline H1 & $\begin{array}{l}\text { Attachment to someone's } \\
\text { intimate social network that } \\
\text { is connected to social media } \\
\text { influences a person's } \\
\text { willingness to self-censor } \\
\text { on social media. }\end{array}$ & \\
\hline \multirow{3}{*}{ H2 } & $\begin{array}{l}\text { The attachment to an } \\
\text { intimate social network of } \\
\text { someone who is connected } \\
\text { on social media influences } \\
\text { the activity of posting one's } \\
\text { politics on social media. }\end{array}$ & \\
\hline \multirow{5}{*}{ H3 } & $\begin{array}{l}\text { Fear of experiencing } \\
\text { isolation on social media } \\
\text { affects one's willingness to } \\
\text { self-censor social media. }\end{array}$ & Significant \\
\hline H4 & $\begin{array}{l}\text { Fear of experiencing } \\
\text { isolation on social media }\end{array}$ & Significant \\
\hline
\end{tabular}




\begin{tabular}{|c|c|c|}
\hline & $\begin{array}{l}\text { influences the activity of } \\
\text { posting one's politics on } \\
\text { social media. }\end{array}$ & \\
\hline H5 & $\begin{array}{l}\text { Perception of the diversity } \\
\text { of political opinions on } \\
\text { social media influences a } \\
\text { person's willingness to self- } \\
\text { censor on social media. }\end{array}$ & Not significant \\
\hline H6 & $\begin{array}{l}\text { Perception of the diversity } \\
\text { of political opinions on } \\
\text { social media influences the } \\
\text { activity of posting one's } \\
\text { politics on social media. }\end{array}$ & Not significant \\
\hline H7 & $\begin{array}{l}\text { Perceptions of future } \\
\text { political opinion trends on } \\
\text { social media affect a } \\
\text { person's willingness to self- } \\
\text { censor on social media. }\end{array}$ & Not significant \\
\hline H8 & $\begin{array}{l}\text { Perceptions of future } \\
\text { political opinion trends on } \\
\text { social media influence the } \\
\text { activity of posting one's } \\
\text { politics on social media. }\end{array}$ & Significant \\
\hline H9 & $\begin{array}{l}\text { A person's willingness to } \\
\text { self-censor on social media } \\
\text { influences the activity of } \\
\text { posting one's politics on } \\
\text { social media. }\end{array}$ & Significant \\
\hline
\end{tabular}

The first multiple linear regression test conducted in the research sub-structure I which measures the influence of social network attachment, fear of experiencing isolation on social media, perceptions of the diversity of political opinions on social media, and perceptions of trends in the development of political opinions on social media on one's willingness to selfcensor on social media. Measurement results show that only fear variables experience isolation on social media which has a direct influence on the willingness to self-censor on social media. Then, for the social network attachment variable, the perception of the diversity of political opinions on social media, and the perception of trends in the development of political opinions on social media did not significantly affect a person's willingness to self-censor on social media based on the results of statistical tests.

Through this test, it was proven statistically that the level of closeness of the relationship between respondents and their relatives connected in the real world and on social media represented by intimate social network attachment variables did not significantly influence the respondents' willingness to censor their opinions about the "Zaadit Yellow Card "To be poured on social media, with the significance value shown is 0.067 above the reference limit of 0.05 . The results of this study are different from the findings from the study of Kwon[2] conducted in the United States. Thus, the research hypothesis (H1) which states that the attachment of intimate social networks influences the willingness to self-censor on social media is rejected.

Furthermore, it was statistically proven that respondents were willing not to share their opinions about the "Zaadit Yellow Card" event on social media so that they would not experience social isolation from their real-world relatives who were also connected with them through the medium, with the significance value indicated 0,000 below the reference limit of 
0.05. Thus, the willingness to self-censor which is an attempt to adjust to the social environment in order to avoid social isolation which is the core of the spiral of silence theory is still undeniable in the scope of social media. The results of this test are similar to the findings from Kim[5] study which explained that fear of experiencing social isolation as a factor causing the effect of spiral of silence in South Korea is still valid. So, by referring to the results of this test the research hypothesis (H3) which states that fear of experiencing isolation on social media influences the willingness to self-censor on social media is accepted.

Other findings from this study indicate that respondents did not pay much attention to the opinions of their relatives about the various "Zaadit Yellow Card" events on social media as a factor that must make them silence their personal opinions about the incident. This is evidenced by the significance value of 0.384 , the value is above the reference limit of 0.05 . Referring to the test results, the research hypothesis (H5) which states that the perception of the diversity of political opinions on social media influences the willingness to self-censor on social media is rejected.

The relationship between the last variables measured in the research sub-structure I is the influence of perceptions on the development trend of future political opinions on social media on the willingness to self-censor on social media. Statistical test results show the significance value between perceptions on trends in the development of future political opinions on social media on one's willingness to censor is 0.143 , above the reference limit of 0.05 so that the effect between these variables can be said to be insignificant. Referring to these results, the research hypothesis (H7) which states that the perception of trends in the development of political opinions on social media influences the willingness to self-censor on social media is rejected.

Subsequent multiple linear regression testing conducted in this study was carried out in the second sub-structure of research that measures the influence of social network attachment, fear of isolation on social media, perception on the diversity of political opinions on social media, perception of trends in the development of political opinions on social media on one's willingness, as well as willingness to self-censor on social media on political posting activities. The measurement results show that the variables of intimate social network attachment, fear of experiencing isolation on social media, perception of trends in the development of political opinions on social media, and willingness to self-censor on social media have a direct influence on political posting activities. Meanwhile, only the perception variable on the diversity of political opinions on social media does not significantly influence political posting activities on social media based on the results of statistical tests. Through the results of the multiple linear regression test, it was found that the fear variable experiencing isolation on social media was the only variable that fulfilled the requirements to measure indirect effects in this study, where these variables showed a significant influence on the willingness to self-censor and post political activity.

The first test result in sub-structure II proves that the linkage of social networks influences political posting activities, where this relationship shows the significance value of 0.024 below the reference limit of 0.05 . These results prove that the level of closeness of the relationship between respondents and their relatives connected in the real world and on social media influences them to express their personal opinions about the "Zaadit Yellow Card" to upload on social media. The test results for this variable are the same as those of Kwon[2]. Thus, the research hypothesis $(\mathrm{H} 2)$ which states that the attachment of intimate social networks affects political posting activities on social media is accepted.

Then for the relationship of fear of experiencing isolation on social media on political posting activities on social media also showed significant results. The significance value generated by the relationship between these variables is 0.032 , below the reference limit of 0.05 . 
But it should be noted that the relationship between these two variables is a reversed relationship, in contrast to the relationships between other variables. The relationship that turns around here means that with increasing fear of isolation on social media, political posting activities will decrease, and vice versa. This reversal relationship is shown through the beta coefficient of -0.157 which arises after the regression test, where the symbol (-) in front of the beta coefficient describes the reversed relationship. Previously, Kim[5] in his research conducted in South Korea also found the type of relationship reversed as in this study. Referring to these results, then $(\mathrm{H} 4)$ which states that the fear of experiencing isolation on social media influences political posting activities on social media is accepted.

Subsequent tests were conducted to determine the effect of perceptions on the diversity of political opinions on social media on political posting activities on social media showing the significance value generated was 0.074 . This value is above the reference limit of 0.05 . Thus, the conclusion that can be drawn is (H6) which states that the perception of the diversity of political opinions on social media influences political posting activities on social media is rejected.

Tests are carried out on perceptual variables on future political development trends on social media with political posting activities. This influence is indicated by a significance value of 0.02 which is below the reference limit of 0.05 . Thus, the research hypothesis (H8) which states that perceptions of trends in the development of future political opinions on social media influence political posting activities on social media are accepted.

The last stage in testing the second sub-structure of research is to examine the relationship between the variables of willingness to self-censor on social media with political posting activities on social media. Statistical test results show that the influence caused by the willingness to self-censor on social media on political posting activities on social media is a comparable inverse influence such as the relationship between fear of experiencing isolation on social media on political posting activities on social media, namely by significance of -0.218 . This can mean that the higher a person's willingness to self-censor on social media, the smaller the level of political posting activity on social media, and vice versa. The relationship between these two variables has a significance value of 0.002 , below the 0.05 limit. Thus, the research hypothesis

Then, based on the results of path analysis, a new path was found that was different from the path proposed through sub-structures I and II. The pathway is the pathway described in the adjusted sub-structure model. In this model, it can be seen that there is no perception variable on the diversity of political opinions on social media. This is because these variables do not have a significant influence on the willingness to self-censor and political posting activities related to "yellow card" events among members of the faculty-level BEM daily board on the UI campus.

Through this model, it can also be seen that the variables of attachment to intimate social networks and perceptions of trends in the development of future political opinions on social media only affect political posting activities on social media. This finding means that the two variables do not significantly influence the formation of a spiral effect on social media, where the two variables illustrate that the respondent is not too concerned about the opinion of his relatives regarding the "yellow card" event and suggests the desire for his opinion on the event to be a dominant opinion with posting political activities on social media. This model can also show that although social media users in Indonesia are not willing to do political posting activities to avoid social isolation which is portrayed through the indirect relationship that occurs between fear of experiencing isolation on social media in political posting activities through willingness to censor themselves on social media (0.012), as well as the direct effects generated 
by fear of experiencing social isolation in political posting activities on social media $(-0.025)$, it can be proved that research respondents were still willing to post political activities related to "yellow card" events in social media. Thus, it can be interpreted that the fear of experiencing isolation on social media is most likely to come from those who are outside the bond of intimate social networks, so that the resulting spiral effect may only apply to certain circles, not from intimate relatives.

\section{Conclusions}

The purpose of this research is to reveal whether the spiral of silence effect still applies to social media users Facebook, Twitter, Instagram, Line, and Whatsapp Indonesia. Since the emergence of digital media, one of the popular media effect theories is indeed very often attract the interest of researchers to test it again, especially in the context of social media. The main research question is then derived into 9 hypotheses which contain a causal relationship between variables that support the spiral of silence effect. Where, to answer these hypotheses the author conducted an online questionnaire on 190 students who joined as daily administrators of the faculty level Student Executive Board at the University of Indonesia campus. The results of the tests carried out in this study indicate that 5 of the 9 hypotheses proposed in this study proved to have a significant influence.

On the other hand, this study also proves that the fear of experiencing isolation is still a good predictor in the creation of a spiral of silence effect among social media users Facebook, Twitter, Instagram, Line, and Whatspp in Indonesia. It can be seen that there is only one variable that affects a person's willingness to self-censor on social media, namely the fear of experiencing isolation on social media. On the other hand, this variable also influences the activities of someone's political posting on social media by showing the results of an inverse comparison. With these results, it is evident that social media users in Indonesia are willing to adjust to the social environment to avoid social isolation.

The results of this study that need to be considered also are the significant relationship between willingness to self-censor in social media on political posting activities by showing an inverse comparison. Where, with the increasing willingness of someone to self-censor on social media, the political posting activity will be lower. The results of the research as described also prove that the core of the spiral of silence theory which states that a person will make social adjustments to avoid social isolation is still undeniable or can still be said to be valid in the scope of Indonesian social media users. However, the model of the classic spiral of silence theory has now been modified because of the urge to self-censor from social users before they express their personal opinions online.

\section{Acknowledgements}

This work is supported by Hibah PITTA 2018 funded by DRPM Universitas Indonesia No.2026/UN2.R3.1/HKP.05.00/2018

\section{References}

[1] M. K. Jennings and V. Zeitner, "Internet use and civic engagement: A longitudinal analysis," Public Opin. Q., vol. 3, no. $311-334$.

[2] K. Kwon, M. Hazel, S. I. Steffanone, and M. A, "Unspeaking on facebook?: Testing networks effects on self-censorship of political expressions in social networks Size," Qual. Quant., vol. 49, no. 4, p. 1417.

[3] E. Noelle-Neumann, The spiral of silence: Public opinion- our social skin, 2nd edition. Chicago: University of Chicago Press. 
[4] G. Petric and A. Pinter, "From social perception yo public expression of opinion: A structural equation modelling approach to spiral pf silence," Int. J. Public Opin. Res., vol. 14 , no. 1 , p. 37 .

[5] S. H. Kim, H. Kim, and S. H. Oh, "Talking about genetically modified (GM) foods in South Korea: The role of the internet in the spiral of silence process," Commun. Soc., vol. 17 , no. 5 , p. 713 . 